\title{
The interaction of age and gender in illness narratives
}

\author{
CLIVE SEALE $*$ and JONATHAN CHARTERIS-BLACK $\dagger$
}

\begin{abstract}
Recognition of the greater capacity of older women to draw on supportive social networks has now supplemented an earlier focus of research into gender and ageing which portrayed older men as a 'privileged gerontocracy' because of their greater access to financial resources and spousal care. This study of the experiences of cancer among people of three different age groups conducted a comparative keyword analysis of their narratives to consider the gender differentiation of a third resource: access to medical information and personnel. The analysed narratives were sampled from a large archive of research interviews. It was found that older men with cancer demonstrated a greater involvement with medicine as an expert system than younger men or women or older women. This stemmed from their social confidence when interacting with doctors and their interest in treating their illness as a 'problem' to be fixed with medico-scientific solutions. Compared with younger men and women of all ages, older men were less likely to draw on informal social and family networks for support, or to discuss in a direct style the emotional dimension of illness experience. Our findings contrast with other studies that have reported linguistic disadvantage in older people in elderly care settings, which underlines the importance of context for linguistic studies.
\end{abstract}

$\boldsymbol{K E} \boldsymbol{Y} \boldsymbol{W O R D S}$ - gender, age, resources, cancer, linguistics, comparative keyword analysis.

\section{Introduction}

The economic disadvantages experienced by older women have been documented in much research on gender and ageing (Arber and Ginn I99I ; Estes 2005). More recently, differences in the social networks of older men and women have been construed as conferring a relative advantage on older women, who have been shown to have wider social and support networks than older men (Arber and Ginn 2005; Arber, Andersson and

* School of Social Sciences, Brunel University, Uxbridge, Middlesex, UK.

$\dagger$ School of Languages, Linguistics and Area Studies, University of the West of England, Bristol, UK. 
Hoff 2007; Russell 2007). By implication, older men are disadvantaged and deficient in this respect, especially if the protective effect of a female partner to make social arrangements and maintain supportive kin and friendship networks is absent (Arber 2004). This is associated with rethinking of an earlier perspective that constituted older men as a 'privileged gerontocracy' because of their economic advantages and greater likelihood of being married or partnered until the time of death (Applegate 1997:4). The consequences of these patterns of advantage and disadvantage are particularly felt at older ages, as illness and disability develop.

There are few studies of how older men and women 'do' gender (Russell 2007). In this paper we report on this through a controlled comparison of older, middle-aged and younger men's and women's linguistic performances of gender in illness narratives. The analysis reveals a dimension hitherto unrecognised by commentators on gender and ageing, although it will be familiar to sociolinguists that study gender and language (Coates 2004; Cameron 2007). The latter field has documented numerous gender-related linguistic patterns but produced few studies of the linguistic correlates of old age (Coupland I997), and seen no significant exploration of the interaction of age and gender. We demonstrate in this paper that older men with serious illness are extensively engaged with medicine as an expert system and have an interest in using it for their personal benefit. To do this, they constitute illness as a technical problem to be solved alone, rather than an emotional experience to be shared with others. In this respect, older men differ from both older women and younger men and women, and this difference is associated with their greater social confidence. Arguably, this ability to draw on biomedicine as a resource confers advantages that have been underplayed in the literature on gender and ageing.

\section{Gender, ageing and language}

Many sociological and social-psychological studies now describe gender differences amongst older people in their capacity to maintain supportive social networks. Allan (2005), for example, reported that women are better at making new friends in later life. From a review of the literature on social networks, Chappell (I989) showed that older women have more expressive and supportive bonds and more intimate contact with others, whereas older men are highly dependent on their wives for such things. Barnes and Parry (2004) found older women's friendships to be more intense, affective, reciprocal and mutually supportive than men's, who were more dependent for these things on partners and, in some cases, children. Jerrome (I993) 
found older men's friendships to be sociable rather than intimate, and to involve less self disclosure than older women's friendships. Wenger et al. (1996) and Victor et al. (2002) found that on the loss of a spouse, older men were more likely to feel lonely, isolated and depressed than older women. Perren, Arber and Davidson (2003) found low levels of membership of informal groups among divorced or never-married men. These findings have contributed to a 'deficit' view of older men, which sees them as less likely to be able to draw on wider sources of informal social support when this is unavailable from an immediate family member.

Studies in the field of linguistics have, in general, examined separately the effects of gender and age. There is a vast literature on gender and language which cannot easily be summarised (e.g. Coates 2004; Speer 2005). Cameron (2003) presented a critical perspective on this field in her account of language ideologies. She noted that studies of gender and language in the 'variationist' linguistics tradition (i.e. looking for variability between groups) are commonly used to support the popular view, as promoted in the mass media and self-help books, that gender differences exist and are natural. Cameron marked the ideological status of these beliefs by noting that the content of such popular stereotypes differs by culture and historical era. Thus current language ideology claims that 'women are more verbally skilled' (Cameron 2007: 7), whereas men are 'inarticulate [and] linguistically unskilled' (Cameron 2003: 454), because of their inability to engage in self-disclosing talk, self revelation, to make admissions of vulnerability, and to produce co-operative rather than competitive interaction. Cameron (2007) sought to undermine the claims of the variationist 'gender difference' tradition and to counter this ideological use of its findings. Perhaps a key strength of her work lies not in challenging this now voluminous evidence base, but in pointing out that research has largely failed to address the influence of the particular context in which talk is produced. The 'gender difference' tradition also tends to involve the assumption that speakers cannot vary their performances of gender because they arise from something inside the person (essentialism) rather than being agentic responses to particular social contexts.

The literature on gender and language has persistently documented the difference (as well as some overlap) between gendered language styles and preferred topics of talk. The consistency of the findings in sociological studies on gender differences in social networks is striking. Work on illness-support groups exemplifies this point. In our study of breast cancer and prostate cancer Internet forums, where people with these illnesses exchange information about their experiences and find support, we found that women's language was more likely to involve expressions of feelings (for example, through superlatives such as 'amazing' or 'brilliant') or to make references 
to their emotional responses to illness (Seale, Charteris-Black and Ziebland 2006). Women also referred to a much wider range of people, while men were more likely to use the forums to gather knowledge. In this respect, our findings were similar to those of other comparative studies of such groups (Gray et al. I996; Klemm et al. I999). At the same time, the influence of context could change these 'performances' of gender. In a separate study of male relatives and friends who were communicating on a breast cancer Internet forum, we showed that the men (many of whom faced the loss of a partner and the obligation to take on family responsibilities) became more emotionally expressive and more interested in speaking about relationships, particularly those with children (Seale 2006). This reminds us that there is nothing fixed or 'essential' about the linguistic performance of gender, and that the influence of context is an important consideration.

Linguistic studies of ageing and language are less common, as Eckert (I997) pointed out when she remarked, 'in sharp contrast to the yearby-year studies of [the language of] children and adolescents, adults have been treated as a more or less homogeneous age mass' (p. I65). Nevertheless, a small research tradition exists and has been summarised by Coupland (1997). The early research focused on establishing whether ageing brought a decline in communicative competence, but with inconclusive results. As Coupland noted, this was 'certainly not altogether bad news for the old' (1997: 29). Such research suffers from a inconsistency about what age to count as 'old' and a lack of specificity about the social contexts in which the studies were conducted. Remedying this latter problem is a strand of linguistic research which focuses particularly on what Coupland called the setting of 'geriatric medicine' (I997: 39). These studies tend to show that the language of older people in elder-care settings reflects low expectations of both the medical benefit and the desirability of becoming involved in medical and health decision-making (see the special issue of this journal introduced by Coupland I99I). Gender has not been a variable in these studies, however, and given the nature of the older population in such care settings, these findings are more likely to apply to older women than men. At the same time, this work suggests the possibility that degrees of social confidence and power in interaction vary across the life course, and that this may advantage the middle-aged rather than the very young or the very old. For this reason, our sample for the empirical study reported here had young, middle-aged and old groups.

Coupland has also helpfully pointed out a phenomenon similar to Cameron's (2003) language ideologies: stereotypes of age-appropriate language circulate in contemporary culture and are at times reproduced 
by older people themselves when they reflect on their own linguistic performance. Such stereotypes, for example, may claim that older people are likely to 'lose the thread' of an argument, or express themselves in terms that indicate a 'grumbly' or 'grouchy' persona. It is our contention that, unlike the field of gender and language, in which attempts like Cameron's to overturn popular stereotypes come up against a large body of research that supports the stereotypes, in the field of language and ageing no such evidence or consensus exists. In both fields, it is important to study local contexts and particular sub-groups (Galasiński 2004). This paper examines certain relationships between age and language performance among a particular group of people, those who have been diagnosed with cancer.

The study of ageing and language presented here takes as its context interviews about the experience of illness and, more specifically, the experience of cancer. The findings counter certain stereotypes about older people's language, particularly in relation to older men who, we will show, bring considerable social confidence to their interactions with expert medical systems. We also show older women's greater concern with relationships, the direct expression of emotion and the maintenance of supportive social networks, although this does not necessarily translate into confidence or interest in interacting with medical specialists.

\section{Method, methodology and materials}

A selection of 102 qualitative interviews with people who narrated their experience of cancer has been systematically analysed by age and gender using both quantitative and qualitative approaches. The IO2 interviews are a sub-sample of a large corpus of $\mathrm{I}, 035$ interview transcripts that were purchased for secondary analysis from the DIPEx project, which collected interviews about illness and health experiences for display on an educational web site. ${ }^{1}$ To enable matched comparisons, the sample of Io2 for analysis was selected by age and gender to form six sub-groups, each with I7 interviews (see Table I). The distribution of types of cancer among the I02 interviewees shown in Table I reflects, broadly speaking, their incidence by age and gender in the general population (Cancer Research 2006). Breast cancer is the most commonly diagnosed, and prostate cancer the fourth most commonly diagnosed. Ovarian cancer is the second most commonly diagnosed women-only cancer, and testicular cancer the second most common men-only cancer. Breast and ovarian cancer are age-related, being rare in women aged less than 40 years, and with over one-half of all cases occurring in women aged $5^{0}$ or more years. 
T A в L E I. Age, gender, diagnosis and word count for the sample analysed

\begin{tabular}{|c|c|c|c|c|c|c|}
\hline \multirow[b]{2}{*}{ Attributes } & \multicolumn{3}{|c|}{ Women } & \multicolumn{3}{|c|}{ Men } \\
\hline & Older & Mid & Young & Older & Mid & Young \\
\hline \multicolumn{7}{|l|}{ Diagnosed cancer: } \\
\hline Brain tumour & - & - & 2 & - & - & 4 \\
\hline Leukaemia & - & - & 2 & - & - & 3 \\
\hline Other childhood cancer & - & - & 7 & - & - & 6 \\
\hline Testicular & - & - & - & - & I4 & 4 \\
\hline Prostate & - & - & - & I7 & 3 & - \\
\hline Breast & Io & 7 & 2 & - & - & - \\
\hline Ovarian & - & Io & I & - & - & - \\
\hline Cervical & 7 & - & 3 & - & - & - \\
\hline Total & I7 & 17 & I7 & I7 & I7 & I7 \\
\hline \multicolumn{7}{|l|}{ Age at interview (years): } \\
\hline Average & 70.3 & $45 \cdot 4$ & 22.4 & 7I.3 & 47.9 & 20.8 \\
\hline Range & $65^{-82}$ & $4^{0-}-54$ & I6-28 & $65-83$ & $4^{0}-55$ & I6-26 \\
\hline Total words (thousands) & II 5.8 & I37.6 & 236.5 & 98.3 & I $46 . \mathrm{I}$ & 202.5 \\
\hline
\end{tabular}

The incidence of cervical cancer peaks at a younger age, but also rises in old age. Prostate cancer affects older men, with more than 6o per cent of cases affecting men aged 70 or more years and rarely being diagnosed in men aged less than 50 years. Testicular cancer tends to affect younger men, with half of all cases occurring to men aged less than 35 years. Leukaemia and brain or spinal tumours are the most common forms of childhood cancer.

The six comparison groups were formed to enable comparisons by gender and across three age groups, with the 'very old' and the 'very young' at the extremes. The interviews were homogeneous in the sense that they are all about cancer experience, but clearly the clinical picture for the various cancers differed, so any age differences that we detect might be associated with the particular condition as well as gender. To address this possibility, we analysed further samples from the archive and controlled for the type of illness experience. These samples were unsuitable for the main analysis because the distribution of different diseases is strongly age-related, meaning that extremes of age could not be compared in an illness-matched sample. The sampling for the subsidiary analyses is reported below where relevant. Other variables may of course be confounded with age in this selection. This is not a random allocation experiment and matching can only take account of known variables that have been measured in the dataset. In particular, we caution that the influences of social class and educational level have not been controlled. It would be difficult to do this given the paucity of information in the dataset 
on the social class variable for younger respondents, and because the original research team collected no information about educational level (it was not required for their purposes). ${ }^{2}$

The text in the I02 interviews amounted to just under one-million words. Women said more than men, old men said the least and young women the most (see 'total words' in Table I). The first step in the analysis was to use computer software to provide what we like to think of as an 'aerial view' of the word patterns across the comparison groups. This involved an initial comparative keyword analysis (Seale, Charteris-Black and Ziebland 2006) using Wordsmith Tools (Scott 2005) to establish which words occurred with high or low relative frequencies. Supplementing and extending this exercise, the texts were semantically tagged automatically using WMatrix software (Rayson 2005), which enabled further comparative analysis of the frequencies of the semantic word groups. Both authors summarised, discussed and interpreted the results, which entailed investigating the particular contexts in which words were used and led to the tabulations presented later. The findings informed the choice of words that were investigated in the qualitative analyses. ${ }^{3}$

We are acutely aware of the limitations of unthinking reliance on quantitative or automated analyses of text (Billig I988), but also resist the unthinking dismissal of quantitative approaches to text analysis. Our own procedures involved an awareness of the need to examine the context in which words were being used. Disambiguation of a range of possible meanings with reference to context is essential in this kind of analysis, and has been done where appropriate. The qualitative analyses represent a descent from the 'aerial view' provided by the statistical overview of word patterns. They allowed a fuller appreciation of individual variability and personal agency, and their findings complement and extend the statistical findings.

Tables 2 to 5 are arranged so that the statistical significance of the overall gender difference is indicated in the rightmost column. The three columns for each gender show the incidence of words per I0,00o for three age groups and the significance of the difference between the oldest and youngest age groups. The words and variations on those words that contribute to each capitalised word cluster label are shown in the table's notes. Thus, Table 2 shows under 'PETS' that 'cat', 'cats', 'dog' and 'dogs' occurred I.8 times per Io, ooo in the words produced by older women, but only 0.3 times per I0,000 in the words produced by younger women. This difference between older and younger women is statistically significant $(p<$ o.oor $)$. Women used these words more than men $(p<$ o.oI $)$. Where space permits, the body of the table contains the actual words contributing to the statistics for that item in lower case (e.g. 'adult/s' in Table 3) rather than using the capitalised cluster labels. 
T A B L E 2. Lifestyle and language-style words per Io,ooo

\begin{tabular}{|c|c|c|c|c|c|c|c|}
\hline \multirow[b]{2}{*}{ WORD CLUSTERS } & \multicolumn{3}{|c|}{ Women } & \multicolumn{3}{|c|}{ Men } & \multirow{2}{*}{$\begin{array}{c}\text { Overall } \\
\text { gender } \\
\text { difference }(p)\end{array}$} \\
\hline & Older & Mid & Young & Older & Mid & Young & \\
\hline YOUNG STYLEA $^{A}$ & 2 III.9 & $3^{10.2}$ & $553 \cdot 4^{* * * *}$ & $247 \cdot 3$ & 29I.I & $605.2^{* * *}$ & $M^{* * *}$ \\
\hline EDUCATION $^{\mathrm{B}}$ & I.9 & 3.0 & I $4.6^{* * * *}$ & 0.7 & 3.7 & I $4.8^{* * * *}$ & n.s \\
\hline SPORT $^{\mathrm{C}}$ & 0.0 & 0.4 & 0.0 & 0.3 & 0.7 & I. $7^{* *}$ & $\mathrm{M}^{* * *}$ \\
\hline $\mathrm{ALONE}^{\mathrm{D}}$ & $3 \cdot 7^{*}$ & 2.2 & 2.2 & I. 4 & І. 6 & $\mathrm{I} .5$ & $\mathrm{~W}^{* *}$ \\
\hline $\operatorname{PETS}^{\mathrm{E}}$ & เ. $8^{* *}$ & 0.3 & 0.3 & 0.0 & 0.5 & O.I & $\mathrm{W}^{*}$ \\
\hline BEING OLD ${ }^{\mathrm{F}}$ & $3.7^{* * * *}$ & 0.9 & $0 . I$ & I. $6^{* *}$ & 0.4 & 0.3 & $\mathrm{~W}^{*}$ \\
\hline DEATH $^{\mathrm{G}}$ & $7.5^{* * * *}$ & 8.I & 3.5 & $7 \cdot 3^{* * * *}$ & 6.2 & 3.2 & n.s \\
\hline RELIGION $^{\mathrm{H}}$ & $2.3^{* * * *}$ & 2.2 & 0.5 & 0.2 & 0.3 & O.I & $\mathrm{W}^{* * * *}$ \\
\hline
\end{tabular}

Notes: W: women more. M: men more. The significance levels given within each gender compare the rates for the youngest and oldest age groups. The individual words in each cluster are as follows:

A: basically, obviously, actually, probably, really, gonna, stuff, yeah, yeh, like, sort of, to be honest, you know, just, kind of.

B: college, exam, GCSE/s, school/s/'s, teacher/s, university/uni. G: cricket, football/s/ers.

D: alone, by myself, on my own. E: cat/s, dog/s. F: elderly, retire/d/s/ment. G: death/'s/s, $\mathrm{dead}, \mathrm{die} / \mathrm{d} / \mathrm{s}$.

H: God/s/'s, church/es ('my/oh/thank God!' and other exclamations excluded).

GCSE is the General Certificate of School Education.

Significance levels: $* p<0.01, * * p<0.001, * * * p<0.0001$, n.s. not significant.

\section{Lifestyle and language style: testing the validity of keyword analysis}

Table 2 shows that younger people had a different language style from older people, as is shown by the results for the YOUNG STYLE word cluster. This was particularly the case for young men, who also displayed exceptional interest in cricket and football. The involvement of younger people with school and university was evident and for this there was no gender difference. Adverbs like 'basically', 'sort of' and 'obviously' play a role in conveying hesitancy or indirectness and in mitigating statements that might otherwise be considered as face-threatening. Thus these words reveal something of the social identity of the speakers. The life situation of some older women was reflected in the distribution of certain other words. Being ALONE and OLD, mentions of DEATH, PETS and RELIGION were all more frequent in the narratives produced by older women, although talk about DEATH was also a concern for older men. In general, the results show that the patterns revealed by comparative keyword analysis reflect quite sensitively the life situations, concerns and preoccupations of men and women of different ages.

\section{Style markers and social confidence}

It is worth spending a little time investigating the YOUNG STYLE words that were used so heavily by younger men, since by understanding 
their function in young people's discourse and social identity we can better understand what older men acquire when they lose these habits of speech. The use of these adverbs has commonly been associated with indirect strategies that reduce the illocutionary force of facethreatening speech acts (Brown and Levinson 1987). Their use by the younger interviewees suggests a social identity that requires them to appear tentative, to hedge and to mitigate the force of the underlying emotional experience of illness. Their relative absence in the speech of older men, in contrast, suggests a less tentative and more socially confident style. For example, the use of 'probably' is a typical form for communicating modality, which is the speaker's strength of commitment to what is being said, often also communicated by modal forms such as 'may', 'might' or 'could'. The intention is to reduce the level of certainty of an utterance, as in the following example: 'it sounds quite morbid but you can probably cope with negative things happening' (YPC 3 I male, aged 28 years).

The adverb 'just' is often used to mitigate a very intense statement. 'Sort of' can also introduce the note of vagueness that is conveyed by generalising, where precision or detail would be more face-threatening. Adverbs that at first appear to strengthen the force of an utterance, such as 'obviously' or 'basically', on examination of their typical contexts are revealed to have the opposite role in speech. For example, 'basically' appears to be a word by which younger speakers protect their face from potentially frightening experiences by simplifying issues relating to illness experience that are in reality not 'basic' at all:

um well I was diagnosed when I was just about I5-and-a-half um with leukaemia which we later found out I had the Philadelphia chromosome as well which can't be treated just by uh radiotherapy it has to, you have to have a bone marrow transplant basically (YPGio male, aged ig years).

The combined effect of these adverbs is to convey the message that everything to do with being male, young and ill is uncertain; that this is the only thing that is certain. As will be shown, the speech of older people, men's in particular, contrasts strongly with this hesitant and muchqualified presentation of self.

\section{Social networks}

It will be recalled that the research literature shows that the informal social networks of older women are more extensive than those of older men. Table 3 displays the words that indicated speakers' mentions of other 
T A B L E 3. Social network words per Io,ooo

\begin{tabular}{|c|c|c|c|c|c|c|c|}
\hline \multirow{2}{*}{$\begin{array}{l}\text { Words or } \\
\text { WORD CLUSTERS }\end{array}$} & \multicolumn{3}{|c|}{ Women } & \multicolumn{3}{|c|}{ Men } & \multirow{2}{*}{$\begin{array}{c}\text { Overall } \\
\text { gender } \\
\text { difference }(p)\end{array}$} \\
\hline & Older & Mid & Young & Older & Mid & Young & \\
\hline PARENTS $^{\text {A }}$ & $7 \cdot 3$ & I2.7 & $28.2^{* * * *}$ & $3 \cdot 7$ & $5 \cdot 3$ & $17.2 * * *$ & $\mathrm{~W}^{* * * *}$ \\
\hline FRIENDS $^{\mathrm{B}}$ & I0.0 & I0.7 & $16.5 * * *$ & $5 \cdot 3$ & 7.5 & I $2.4^{* * * *}$ & $\mathrm{~W}^{* * * *}$ \\
\hline adult/s & O.I & o & I. $3^{* * *}$ & O.I & 0.1 & $2.0^{* * *}$ & n.s \\
\hline SIBLINGS $^{\mathrm{C}}$ & $7 \cdot 3$ & 6.8 & 5.7 & 0.7 & 2.5 & $4.0^{* * * *}$ & $\mathrm{~W}^{* * * *}$ \\
\hline CHILDREN $^{\mathrm{D}}$ & I3.0* & 17.7 & 9.6 & 4.8 & $7 \cdot 3$ & $8 . I^{* *}$ & $\mathrm{~W}^{* * * *}$ \\
\hline GRANDCHILDREN & I. $5^{* * * *}$ & 0.2 & o & I. $4^{* * * *}$ & 0.2 & O.I & n.s. \\
\hline GRANDPARENTS $^{\mathrm{F}}$ & 0.6 & 0.5 & 0.9 & 0.6 & 0.3 & 0.3 & $\mathrm{~W}^{*}$ \\
\hline husband/s/'s & I0. $8^{* * *}$ & I2.4 & 0.5 & 0.7 & 0.4 & O.I & $\mathrm{W}^{* * * *}$ \\
\hline wife/wives/'s & I. $0^{*}$ & 0.7 & 0.2 & $9 \cdot 5^{* * * *}$ & 7.8 & I.o & $M^{* * *}$ \\
\hline family/ies & $8.7^{* *}$ & 7.3 & 5.6 & $5 \cdot 4$ & 6.0 & 6.0 & n.s. \\
\hline CARE AND SUPPORT $^{\mathrm{G}}$ & $27.2^{* * *}$ & 26.0 & I6.o & $9 \cdot 3$ & 16.8 & $\mathrm{I} 4.5^{* *}$ & $\mathrm{~W}^{* * *}$ \\
\hline
\end{tabular}

Notes: W: women more. M: men more. The significance levels given within each gender compare the rates for the youngest and oldest age groups. The individual words in each cluster are as follows:

A:dad/s/'s/dy,father,mother,mum/s/'s,parent/s/'s. B:boyfriend/s,friends, girlfriend/s,mate/s/'s. C: brother/s/'s, sister/s/'s. D: child/ren/s/'s, kid/s, daughter, son, baby/ies.

E: grandchildren/son/sons/daughter/daughters. F: grandfather/dad, grandmother/ma, gran, grandparents.

G: care/d/s/ing/er/ers, help/ed/ful/ing/s, look after, support/ive/ed/s/ing.

Significance levels: $* p<0.01, * * p<0.001, * * * p<0.0001$, n.s. not significant.

people. The rightmost column indicates that all of the significant overall gender differences apply to women's more frequent use of these words (with the exception of 'wives'). Words referring to PARENTS, FRIENDS and adults were used more by young people, while GRANDCHILDREN and spouses were used more by older people. While amongst men, SIBLINGS and CHILDREN were referred to more frequently by the young, amongst women there was a negligible difference between old and young, although middle-aged women referred to CHILDREN a great deal. The importance of 'family' for older women is demonstrated by their particularly high use of these words; the same is true of the GARE AND SUPPORT cluster. Older men were the least likely to use CARE AND SUPPORT words or to refer to PARENTS, FRIENDS, SIBLINGS, CHILDREN or families, but the most likely to refer to wives. Thus it seems that their social and support networks, or at least the significance they accorded to these when narrating their illness, reduced with age and distinguished them from older women. Younger men, by contrast, mentioned a wide range of people and, in this respect, were similar to younger women. The contrast between older and younger men is illustrated by the following quotations. The first by a younger man 
described the support he received from others during the early stages of his illness:

it was kind of like a bit breathtaking knowing that um you, your friends thought that much of you to like go out of their way to find stuff out for you and um like understand what it is like, so, so they can help you through it and stuff ... friends, they're amazing, they're like um all, all through like my hospital and stuff they were really supportive, um and you don't realise how many friends you actually have until like something like this happens. And I'm really close to all my friends, we're like, I talk to them about anything really. ... My family are really supportive, I used to see all my family and stuff, they used to all come and visit me, um even my cousins and stuff like this, and um my friends and stuff used to come and see me all the time. So yeah, but they, they kind of had put their life on hold, like they, they um, they, they just kind of like stopped everything, my Dad stopped working for a while, so did my Mum just to look after me and make sure like everything was okay with me, so (YPCio male, aged ig years).

By contrast, an older man was asked by the interviewer whether at the point of diagnosis he had discussed it 'with other wider members of the family; were they made aware of the diagnosis?' He replied:

Man: Only with my wife, we didn't spread the decision round other people, no. As far as we were concerned it was a decision between us, and I think my wife would've said that it was my decision anyway, and she would support me in whatever I decided to do.

Interviewer: But did you tell wider members of the family what was going on?

Man: At that stage no er not during the diagnostic period. Once I had decided to have the operation, yes then I informed, all my children were informed, yes ( $\mathrm{P}_{33}$ male, aged 72 years).

The only other time during this informant's interview that he mentioned members of his family was when he recounted that he had tried to persuade his sons that checking for prostate cancer is a good idea. The patterns shown in Table 3 largely reflect understandable life course and gender differences that are well documented in the research literature on gender and social networks. The interaction of age and gender is perhaps most noteworthy when considering the decreased frequency with which men, as they age, talked about other people (apart from their wives) and about care, help and support. Older women, by contrast, were more likely than younger women to speak about these things.

\section{Emotions, expressivity and self-revelation}

Differences in perceptions of the emotional component of illness experience are revealed by the incidence of the pertinent word clusters (Table 4). As with words referring to people, women tended to use more words in 
T A в L E 4. Emotions, expressivity and self-revelation words per Io,ooo

\begin{tabular}{|c|c|c|c|c|c|c|c|}
\hline \multirow[b]{2}{*}{ WORD CLUSTERS } & \multicolumn{3}{|c|}{ Women } & \multicolumn{3}{|c|}{ Men } & \multirow{2}{*}{$\begin{array}{c}\text { Overall } \\
\text { gender } \\
\text { difference }(p)\end{array}$} \\
\hline & Older & Mid & Young & Older & Mid & Young & \\
\hline STRUGGLE $^{A}$ & I5.9 & 18.2 & I6.o & 4.9 & 10.3 & $18.2^{* * * *}$ & $\mathrm{~W}^{* * * *}$ \\
\hline NEEDS $^{\mathrm{B}}$ & 64.7 & 70.9 & 8I. $6^{* * * *}$ & 36.6 & 52.4 & $71.8^{* * *}$ & $\mathrm{~W}^{* * * *}$ \\
\hline FEAR/HORROR ${ }^{\mathrm{C}}$ & пा. 8 & $\mathrm{I} 3.5$ & II. 8 & 4.7 & 7.5 & 6.4 & $\mathrm{~W}^{* * * *}$ \\
\hline ANGER/HATE ${ }^{\mathrm{D}}$ & 2.7 & 2.5 & 3.0 & 0.4 & I. 4 & $2.7 * * *$ & $\mathrm{~W}^{* *}$ \\
\hline MISERY/CRYING ${ }^{\mathrm{E}}$ & $7 \cdot 3$ & I0.8 & II.O** & I.7 & 4.2 & $7.7^{* * * *}$ & $\mathrm{~W}^{* * * *}$ \\
\hline LOVELY/NICE & 6.0 & $5 \cdot 7$ & II. $5^{\text {*** }}$ & 2.0 & 4.0 & $4.9^{* * *}$ & $\mathrm{~W}^{* * * *}$ \\
\hline THANKS $^{\mathrm{G}}$ & $2.8^{* *}$ & $\mathrm{I} .2$ & I.I & I.I & I. 6 & 0.99 & n.s \\
\hline $\mathrm{I} / \mathrm{ME} / \mathrm{MINE}^{\mathrm{H}}$ & 849.3 & 833.3 & 840.0 & 680.2 & 698.4 & $769.2^{* * * *}$ & $\mathrm{~W}^{* * * *}$ \\
\hline STRANGE/WEIRD ${ }^{\mathrm{I}}$ & 0.4 & 2.0 & $5.0^{* * * *}$ & 0.9 & 2.9 & $6.5^{* * *}$ & $\mathrm{M}^{*}$ \\
\hline WORRY/CONCERN ${ }^{J}$ & 12.0 & 9.9 & 9.I & $20.4^{* * * *}$ & I2.9 & $\mathrm{I} 4.2$ & $M^{* * *}$ \\
\hline
\end{tabular}

Notes: W: women more. M: men more. The significance levels given within each gender compare the rates for the youngest and oldest age groups. The individual words in each cluster are as follows:

A: brave/ery/er, cope/ing/s/d/er, faith, fight/er/s/ing, fought, strength, stronger/est, battle/s/ed/ ing, beat/ing/s, try/ied.

B: feel, felt, need/ed/s/ing, want/ed/s. C: afraid, fright/en/ed/ingly/ing, horrible, horror, horrify/ied/ying, panic/s/ked, scare/d/s/y/iest/ily/ier, shocked, terrify/ied, terror. D: angry, anger, annoy/ed/ing/ance/s, hate/d/s/red.

E: cried, cry/ing, depress/ed/ing, despair, gutted, hard/er/est. F: lovely, nice.

G: grateful/itude, thank/ful/ed/s/fully. H: I/'d/'ll/'m/ve, me, mine, myself.

I: strange, weird/ly. J: anxious/iety, concern/ed/s, disconcerting/ed, disturbed/ing/s, worry/ied/ ies/ing/ier.

Significance levels: $* p<0.01, * * p<0.001, * * * p<0.000 \mathrm{I}$, n.s. not significant.

most of these categories, which supports the findings of many sociolinguistic studies that women display greater interest in talk about emotions and in self-revelation (indicated by words in the I/ME/MINE cluster). The exceptions here were STRANGE/WEIRD and WORRY/ CONCERN words. The former were particularly associated with young men and the latter with older men. Apart from THANKS and gratitude words, which associated with older women, many other words referring to the emotions were most used by younger people, with younger men being more likely than older men to use the first person I/ME/MINE pronouns. In fact, old and young men were more often different from each other than were older and younger women. This placed older men once again in an interesting position. On most categories, except the somewhat emotionally restrained WORRY/CONCERN words, older men were the least likely to engage in this kind of talk. Illustrative of differences in emotional expressivity are the following two accounts of responses to news of the diagnosis of cancer. The first was by a young woman who was told that she had breast cancer at the age of 18 years:

But the fact is I was so shocked because I wasn't expecting it whatsoever that I didn't do anything. I just sat deadly still and I didn't know what to do. It was 
awful because no one [friends or family] was there, and then they [the clinicians] went out the room and they went into the office and they left me on my own in that little room and that's when I burst into tears. That's when, that's when the reality hit me. And you get all these things going through your mind, you know. How long have I got? That was the first question, you know. Is it terminal? Am I going to die, you know? What are my chances? You get all these thoughts. ... I just, I wanted someone to blame really. And it's, you can't find anybody because no one's given you it, you know (BGi5 female, aged i9 years).

Contrast this account of the emotional shock of the news with this much more restrained account by the 72 -year-old man who we quoted earlier. He described his restricted approach to the sharing of decision making about his illness. When asked, 'What impact [did the diagnosis have] on you and your wife at the time?', he replied:

Well the impact on me was er if I've got cancer, what can I do about it? The impact on my wife I should think - when I walked out and told, and said I had cancer - was fairly sudden but there is no way of cushioning these kind of things. You know you've either got something or you haven't, you can't, you can't hide it in words. You can only say, 'Yes, I have cancer' ( $\mathrm{P}_{33}$ male).

In this quotation there is a disparity between the speaker's claimed directness with which he informs his wife of a diagnosis and the rather indirect 'off the record' strategy for expressing his feelings by generalisation with the impersonal pronoun 'you'. Thus he is being direct about the act of informing, but using a distancing strategy in relation to the emotional content, or illocutionary force of his language. Such distancing strategies are not untypical of men when describing their illness experience (Charteris-Black and Seale 2008).

\section{Involvement with medical information and personnel}

Table 5 shows that the men's language reflected a marked preference for words associated with gathering information and evidence, making informed decisions, and the effectiveness or success of procedures or actions. Their preference for 'problem' and 'situation' suggests that they looked upon their experience as a problem to be solved with the aid of information that they gathered. For example, the following quotation indicated an action-oriented approach towards the man's 'problem':

Oh yes, oh yes, if there is a problem fix it. You know I'm not the specialist, I'm only the recipient of the speciality and if there's something there that's definitely wrong and I was aware that there was something definitely wrong then we'd got to do something about it (Pio male, aged 69 years). 
T A в L E 5. Medical information and personnel words per Io,ooo

\begin{tabular}{|c|c|c|c|c|c|c|c|}
\hline \multirow{2}{*}{$\begin{array}{l}\text { Words or } \\
\text { WORD CLUSTERS }\end{array}$} & \multicolumn{3}{|c|}{ Women } & \multicolumn{3}{|c|}{ Men } & \multirow{2}{*}{$\begin{array}{c}\text { Overall } \\
\text { gender } \\
\text { difference }(p)\end{array}$} \\
\hline & Older & Mid & Young & Older & Mid & Young & \\
\hline \multicolumn{8}{|l|}{ Information: } \\
\hline ADVICE/INFO & 10.5 & 9.6 & $9 \cdot 5$ & $21.1 * * *$ & 2I.I & I0.5 & $M^{* * *}$ \\
\hline article/s. read/ing/s & $6 . \mathrm{I}$ & 6.2 & 4.6 & $\mathrm{I} 2.2^{* * * *}$ & 6.2 & I.4 & n.s \\
\hline AWARE/CHOICE & 9.I & го.6 & $9 \cdot 2$ & $18.3^{* * *}$ & I3.3 & 9.2 & $M^{* * *}$ \\
\hline INTERNET $^{\mathrm{C}}$ & 0.9 & I.7 & $2.0^{*}$ & 2.1 & 4.6 & 2.0 & $M^{* *}$ \\
\hline SUCCESS $^{\mathrm{D}}$ & 0.9 & 0.9 & 0.5 & $4 \cdot 9^{* * *}$ & $3 \cdot I$ & 0.7 & $M^{* * *}$ \\
\hline problem/s, situation & $7 \cdot 9$ & II. 5 & $5 \cdot 4$ & $28.2^{* * *}$ & I $4 . \mathrm{I}$ & 8.I & $\mathrm{M}^{* * *}$ \\
\hline \multicolumn{8}{|l|}{ Medical personnel: } \\
\hline DOGTOROLOGYE & $8.6^{* * *}$ & 8.5 & 2.2 & $8.0^{* * *}$ & 10.2 & I.I & n.s. \\
\hline SPECIALIST DOG & I0.9*** & 3.2 & $4 \cdot \mathrm{I}$ & $18.7^{* * * *}$ & 9.2 & $5 \cdot 3$ & $M^{* * *}$ \\
\hline GENERAL DOGG & 3.1 & 4.7 & 2.8 & $10.5^{* * *}$ & 8.0 & 2.2 & $M^{* * *}$ \\
\hline doctor/s/'s/doc & I5. 6 & I5.6 & I3.4 & $\mathrm{I} 4.5$ & $\mathrm{I} 3.8$ & I 4.9 & n.s. \\
\hline nurse/ed/ing/s & $10.2 *$ & I9.7 & 6.1 & 5.4 & 7.0 & 5.9 & $\mathrm{~W}^{* * * *}$ \\
\hline
\end{tabular}

Notes: W: women more. M: men more. The significance levels given within each gender compare the rates for the youngest and oldest age groups. The individual words in each cluster are as follows:

A: advice/ise/ised/ing/able/or/ability, evidence, explain/anation/ed/ing, informed/ation, opinion/s, research, technology/ist/ies, terminology, science/tific/tists/'s/ifically. B: aware, choice/s, choose/es/ing, chose/en, control, decision/s/ide/ides/ided, option/s. C: computer, internet, web/ site. D: effective/ly/ness, success/ful/fully/es.

$\mathrm{E}$ : includes all medical specialties ending in 'ology/ist/ists in corpus (e.g. urology, oncologist etc.).

F: consultant/s/'s, specialist/s. G: general practice/practitioner, GP/s/'s.

Significance levels: $* p<0.01,{ }^{* *} p<0.001,{ }^{* *} p<0.000 \mathrm{I}, \mathrm{n} . \mathrm{s}$. not significant.

This interviewee made quite explicit the link between his approach to his body and illness and his work identity as an ex-engineer:

I suppose I've always tried to treat the problem positively. If there's a problem, solve it ... that's my engineering background, because I'm a problem solver. That's my forté, give me a problem and I'll solve it within the sphere of my interest that it and experience. And so I treat that very much in the same way medically [having acted to take my blood pressure down] ... you know if you tell me what the problem is then we get on and deal with it (PIo male, aged 69 years)

With the exception of computing and INTERNET words, which appeared to interest middle-aged men most of all, Table 5 shows that it was older men who particularly participated in this discourse. We have argued elsewhere that such indirect strategies may be ways of 'doing illness' by keeping an emotional distance and concealing their own intimate feelings (Charteris-Black and Seale 2008). Such an 'objective' performance of illness by men may be a way of indexing masculinity.

Table 5 shows no such association with age for women. Men were also significantly more likely to refer to 'consultants', 'specialists' and 'general 
practitioners'. Mentions of these and of named medical specialties were significantly higher for older men. The fact that 'doctors' were mentioned at a similar rate across all age and gender groups suggests that it is particularly important to the men that doctors are distinguished by their specialist knowledge. The confident way in which such men conducted their relationships with their doctors is indicated in the extracts below. In the next extract, the interviewee gave explicit advice on the strategies he had used to address the power asymmetries that he encountered in his relations with the consultant:

No I don't try complementary. I don't trust them myself, I'd sooner go by what the consultant says. Oh here's a tip: when you go and see the consultant, write down all the questions you want to ask him, make a list of the questions, searching questions, get him interested in talking to you. You'll find that consultants just tell you things but if you want to find out, be impertinent and make him squirm a bit when you talk to him, and you'll find you get on a lot better with your consultant, you know. They come down to your level then. They've got this air, you're a piece of meat, I'll sort you out but ask some questions and don't be frightened of them and write down the answers too, but make a list out, it is a very good tip, that ( $\mathrm{P}_{5}$ I male, aged 72 years $)$

The next quotation makes it clear that the consultant's role is to certify a decision taken by the speaker without prior influence by the consultant:

[I said] 'now in your opinion have I made the right decision?' He said, 'Well if you were my dad, that's what I'd want you to do'. So I said, 'Well that's fair enough'. I said, 'I appreciate that you didn't influence me one way or the other but it is nice to know and it's encouraging to me to know that you have, that you do think I've made the right decision' (Po5 male, aged 68 years).

Table 5 shows that nurses were mentioned significantly more often by women and somewhat more often by older women, suggesting that they placed a relatively high priority on care as opposed to specialist medical advice. Comparing young men and young women on these 'information' words reveals few marked differences, but the oldest men showed consistently large differences when compared with women of the same age. The same was true for the use of the terms 'consultant', 'specialists' and 'general practitioner', confirming that this discourse was particularly associated with older men. One can interpret this as a 'command and control' discourse, because it suggests a confident social identity that pursued an inquiring and problem-solving approach to illness, in which an external perspective was adopted. The approach prioritised the search for medical information and communications with specialist doctors, with the aim of presenting the speaker as a wellinformed decision-maker. 


\section{Gender or type of illness?}

It may be objected that gender and type of illness are confounded in the analysis. For example, all of the oldest men suffered from prostate cancer. Perhaps the variety of treatments available for this condition means that engagement with medical ideas and personnel is a particular requirement, so that it is the type of illness rather than the gender of the respondent that is responsible for the frequent use of such words. Against this argument one can point to the fact that there is as much variety in the treatments available for breast cancer as for prostate cancer. For example, a choice between breast-conserving surgery and a total mastectomy may need to be made, just as in prostate cancer there may be a choice between active monitoring or surgery. In both diseases, too, there are controversies in the medical literature about the merits of screening. The fact that a culture of patient choice and patient involvement in medical decision-making has grown up around prostate cancer arguably says more about gender expectations than about the different treatments for these diseases.

The issue can be investigated further by comparing groups with similar illnesses, which is possible to a limited extent from the available archive of interviews. To test the proposition that the differences between older and younger men might have arisen from the type of illness, a comparison was made between two age groups of men who told the story of their testicular cancer: eight men with an average age of 53.3 years (range $5^{\mathrm{I}^{-}} 55$ ), and eight men with an average age of 25.0 years (range $2 \mathrm{I}^{-28}$ ). Those words that we had found to be used with significantly different frequencies by older and younger men were examined (as identified in Tables 2 to 5). During the interviews with men diagnosed with testicular cancer, YOUNG STYLE words 'like', 'yeah' and 'obviously' were significantly more common amongst those aged in the 20 s than those aged in the 5os. Other words confirmed the capacity of keyword analysis to capture key features of the lives led by men of different ages. For example, the following were all used significantly more frequently by those aged in the 20 (school, university, cricket, football, dad, father, mum, parents, friends, girlfriend, brother, kids, family, try, nice, me, web and website). Turning to the medical information words (Table 5), they were indeed used significantly more frequently by men aged in the 50 s than by those in their 2os. For example, men aged in the 5os used 'radiology', 'radiologist', 'specialist', 'article', 'read' and 'problem' more than men aged in the $20 \mathrm{~s}$ (who used 'explain' more). This provides support for the view that gender and age, rather than type of illness, was responsible for older men's interest and involvement with medical ideas and personnel. 
Nevertheless, the findings from studies of 'geriatric' settings (as reviewed by Coupland and Coupland i994), that older people lack involvement in decision making and have low expectations of medical endeavours, should not be discounted. They probably reflect the particular samples and contexts of these studies - they involved groups of very old and 'frail' individuals rather than people with cancer diagnoses. As shown earlier in the analysis of YOUNG STYLE markers, younger men adopted a particularly hesitant and self-effacing style, which older men were the least likely to use. This provides further support for the view that the older men were characterised by social confidence, and that this feature of their style fed into a distancing and problem-solving approach to illness that associated with frequent communication with specialist doctors and scientificallygrounded information, and relatively high expectations of the benefits they would gain through such involvement.

\section{Discussion}

This paper's systematic comparisons have shown that people with a cancer of different age and gender stress different aspects of their cancer experiences and use different linguistic styles. In particular, the social identity of older men differs in key respects from those of older women and younger people. Young people's style of speech and choice of words, particularly young men's, reflects a hesitant and somewhat unconfident social identity that stresses dependency on the support of a wide circle of family and friends during a profoundly unsettling and fear-inducing experience. The findings confirm those of other studies of gender and ageing, in showing that women, particularly older women, are more concerned with the maintenance of supportive social networks and to express their emotional reactions to the experience of illness. Older men, by contrast, expressed the least interest in social network and emotional dimensions, and adopted distancing strategies such as generalisation and the reification of emotional experience. Our findings might be accepted as consistent with Coates's (2002) observation about the generality of men, that when they tell stories their narratives tend to focus more than women's on their own central action roles, with fewer mentions of other people, particularly women, and a reluctance to describe vulnerability.

Older men are particularly likely to see themselves as information gatherers, and to treat their illness as a problem to be solved and their doctors as providers of information that will help them do this. Their interest in relationships and emotions is quite limited, because they conceive the illness experience as an individual quest for technical mastery, to 
be achieved through the application of good-quality medical information and treatments. In pursuing this course, they draw on the considerable resources associated with a mature and relatively confident masculine social identity, which enables them to communicate with doctors in a way that requires the doctors to address the men's information needs. As well as generally fitting the pattern described by Connell (2005) as 'hegemonic' masculinity, in this respect older men also conform to a classic 'expert patient' identity. This finding contrasts with those from linguistic studies of 'geriatric' care (as reviewed by Coupland and Coupland 1994). The latter focus on frail or vulnerable sectors of the older population rather than people with cancer experience and arguably do not differentiate sufficiently between older men and women.

The younger men that we have studied had a somewhat unconfident social identity that derived primarily from their youth and was exacerbated by the experience of facing a life threatening illness at an age when such illnesses are rare. They were struggling with the experience, and their language was less differentiated from that of women of the same age than from that of older men. As men age, and particularly as they enter old age, many find that their social worlds shrink, which means that older men and women appear particularly different from each other. This observation fits superficially at least with the deficit model of older masculinity that has recently been promoted from the gender and ageing perspective (Arber et al. 2007; Russell 2007), and which recognises the greater skills of older women in social networking. Yet the social confidence of the older men we have studied appears to help them exploit sources of medical information, which they use to pursue a strategic and problem-solving approach to their illness. This capacity to draw on medical expertise as a resource, and to participate in medical discourse, is both a source and a reflection of social power in older men's relations with the medical system. In this respect, the older men in this study possessed resources that were less often deployed by older women.

It is possible, of course, that social class and educational level also play a role. For the reasons explained in the methods section, it was difficult to control these factors in the research design. The distribution of the rough scores for social class that we coded for a large proportion of the sample suggests that the DIPEx interviews over-represented those of higher social class and with more education. We have no reliable evidence to suggest strong differences between our six comparison groups on these factors. Nevertheless, in the light of analyses of the influence of social class reported elsewhere (Seale and Charteris-Black 2008), it seems plausible that many of the older men in this study derived their social confidence from a lifetime's experience of holding positions of authority at work. 
Much of the literature on ageing and language has been dedicated to showing that linguistic performance is relatively low in undifferentiated groups of older people, and customarily associates this with the age group's presumed low social engagement and power. Our findings by contrast are consistent with the findings of Miner-Rubino, Winter and Stewart (2004), who found growing levels of 'identity certainty' and 'confident power' amongst men as they aged, with those aged 6o or more years having higher scores on these measures than men aged in the 4os. It explains the paradox reported by Kulik and Bareli (1997) in their study of marital relationships before and after retirement. Commenting on their finding that men become more dependent on their wives' expressive resources after retirement, they observed that this 'seems to contradict' (p. 57I) their reports of greater social power in older ages. Our findings suggest that confidence and social power are a particular feature of many older men's lives, and are expressed in ways that do not necessarily involve the maintenance of extensive social networks.

It seems to us that the particular context of cancer (though not necessarily of prostate cancer) has been effective in bringing this out. Linguistic and other studies of ageing and gender nowadays increasingly recognise that both gender and age-identity are to a large extent 'constructed' in relation to particular contexts. Our study shows that in the context of cancer narratives collected in research interviews, older men demonstrate a performance of gender that is particularly differentiated from other groups, revealing their capacity to draw on resources that deserve greater recognition by those interested in gender and ageing.

\section{Acknowledgements}

This study was supported by a grant from the UK Economic and Social Research Council (RES-o62-23-0130). We are grateful to them, to the DIPEx organisation that collected the original interviews, and to the interviewees who participated.

\section{NOTES}

I The DIPEx charity's website was launched in July 200 I with hypertension and prostate cancer pages, since when it has been extensively developed with many additional illnesses/conditions. The interviews were collected in the United Kingdom during 200I-05 (prostate cancer 2000-OI; breast cancer 200I; testicular and cervical cancer 200I-2002; ovarian cancer 2003; teenage cancer 2004-05). For more details of the DIPEx project and videos of all the interviews, visit the web site (www.dipex.org.uk). The numbering of the interviews in this paper follows that on the web site, so readers interested to watch and hear these interviewees can do so by visiting the site. Full informed consent was given by the interviewees for the use of their transcripts for research purposes. 


\section{I044 Clive Seale and Jonathan Charteris-Black}

2 Readers interested in the impact of social class on language use in another sub-sample taken from this data archive may consult Seale and Charteris-Black (2008).

3 Readers interested in keyword analysis as a method may consult Baker (2006).

\section{References}

Allan, G. 2005. Family Life. Blackwell, Oxford.

Applegate, J. S. I997. Theorizing older men. In Kosberg, J. I. and Kaye, L. W. (eds), Elderly Men: Social Problems and Professional Challenges. Springer Publishing Company, New York, I-I5.

Arber, S. 2004. Gender, marital status and ageing: linking material, health and social resources. Fournal of Aging Studies, r 8, I, 9I-Io8.

Arber, S. and Ginn, J. I99I. Gender and Later Life: A Sociological Analysis of Resources and Constraints. Sage, London.

Arber, S. and Ginn, J. 2005. Gender dimensions of the age shift. In Johnson, M. L. (ed.), The Cambridge Handbook of Age and Ageing. Cambridge University Press, Cambridge, 527-37.

Arber, S., Andersson, L. and Hoff, A. 2007. Changing approaches to gender and ageing. Current Sociology, 55, 2, I47-53.

Baker, P. 2006. Using Corpora in Discourse Analysis. Continuum, London.

Barnes, H. and Parry, J. 2004. Renegotiating identity and relationships: men and women's adjustments to retirement. Ageing \& Society, 24, 2, 213-33.

Billig, M. I988. Methodology and scholarship in understanding ideological explanation. In Antaki, C. (ed.), Analysing Everyday Explanation: A Case Book of Methods. London, Sage, I99-2I5.

Brown, P. and Levinson, S. I987. Politeness: Some Universals in Language Usage. Cambridge, Cambridge University Press, Cambridge.

Cameron, D. 2003. Gender and language ideologies. In Holmes, J. and Meyerhoff, M. (eds), The Handbook of Language and Gender. Blackwell, Oxford, 447-67.

Cameron, D. 2007. The Myth of Mars and Venus. Oxford University Press, Oxford.

Cancer Research 2006. Cancerstats: Incidence UK. Cancer Research UK, London. Available online at info.cancerresearchuk.org/cancerstats/incidence/ [Accessed i8 February 2008].

Chappell, N. I989. Health and helping among the elderly: gender differences. Fournal of Aging and Health, I, I, IO2-20.

Charteris-Black, K. and Seale, C. 2008. Men and the expression of emotion: evidence from illness experience. Gender and Language, 2, 2, forthcoming.

Coates, J. 2002. Men Talk: Stories in the Making of Masculinities. Blackwell, Oxford.

Coates, J. 2004. Women, Men and Language: A Sociolinguistic Account of Gender Differences in Language. Pearson Education, London.

Connell, R. W. 2005. Masculinities. Polity, Cambridge.

Coupland, N. I99I. Preface: sociolinguistic issues in ageing. Ageing E् Society, I I, I, 99-IO2.

Coupland, N. 1997. Language, ageing and ageism: a project for applied linguistics? International Journal of Applied Linguistics, 7, I, 26-48.

Coupland, N. and Coupland, J. I994. Age-identity and health-identity in geriatric medical discourse. In Lauritzen, S. O. and Sacks, L. (eds), Health Care Encounters and Culture: Interdisciplinary Perspectives. Swedish Immigration Institute and Museum, Stockholm, Sweden, 89-128.

Eckert, P. 1997. Age as a sociolinguistic variable. In Coulmas, F. (ed.), The Handbook of Sociolinguistics. Blackwell, Oxford, I5 $1-67$. 
Estes, C. 2005. Women, ageing and inequality: a feminist perspective. In Johnson, M. L. (ed.), The Cambridge Handbook of Age and Ageing. Cambridge University Press, Cambridge, $552-62$.

Galasiński, D. 2004. Men and the Language of Emotions. Palgrave, London.

Gray, R., Fitch, M., Davis, C. and Phillips, C. I996. Breast cancer and prostate cancer self help groups: reflections on differences. Psycho-oncology, 5, 2, I37-42.

Jerrome, D. 1993. Intimate relationships. In Bond, J., Coleman, P. and Peace, S. (eds), Ageing in Society: An Introduction to Social Gerontology. London, Sage, 226-54.

Klemm, P., Hurst, M., Dearholt, S. L. and Trone, S. R. i999. Gender differences on Internet cancer support groups. Computers in Nursing, I 7, 2, 65-72.

Kulik, L. and Bareli, H. Z. 1997. Continuity and discontinuity in attitudes toward marital power relations: pre-retired vs retired husbands. Ageing Eீ Society, I 7, 5, 57I-95.

Miner-Rubino, K., Winter, D. G. and Stewart, A. J. 2004. Gender, social class and the subjective experience of ageing: self-perceived personality change from early adulthood to late midlife. Fournal of Personality and Social Psychology, 3o, I2, I599-6io.

Perren, K., Arber, S. and Davidson, K. 2003. Men's organisational affiliations in later life: the influence of social class and marital status on informal group membership. Ageing $\mathbb{E}^{\circ}$ Society, 23, I, 69-82.

Rayson, P. 2005. Wmatrix: A Web-based Corpus Processing Environment. Computing Department, Lancaster University, Lancaster, Lancashire. Available online at http:// ucrel.lancs.ac.uk/wmatrix// [Accessed i8 February 2008].

Russell, C. 2007. What do older women and men want? Gender differences in the 'lived experience' of ageing. Current Sociology, 55, 2, I73-92.

Scott, M. 2005. Wordsmith Tools 4.o. Oxford University Press, Oxford. Available online at www.lexically.net/wordsmith/version4 [Accessed I8 February 2008].

Seale, C. 2006. Gender accommodation in online cancer support groups. Health, ro, 3, $345^{-60}$.

Seale, C., Charteris-Black, J. and Ziebland, S. 2006. Gender, cancer experience and internet use: a comparative keyword analysis of interviews and online cancer support groups. Social Science and Medicine, 62, Io, 2577-90.

Seale, C. and Charteris-Black, J. 2008. The interaction of class and gender in illness narratives. Sociology, 42, 3, 455-71.

Speer, S. 2005. Gender Talk: Feminism, Discourse and Conversation Analysis. Routledge, London.

Victor, C., Scambler, S., Shah, S., Cook, D., Harris, T., Rink, E. and de Wilde, S. 2002. Has loneliness amongst older people increased? An investigation into variations between cohorts. Ageing \& Society, 22, 5, 585-98.

Wenger, G. C., Davies, R., Shahtahmasebi, S. and Scott, A. I996. Social isolation and loneliness in old age: review and model refinement. Ageing E Society, r6, 3, 333-58.

Accepted 2 I February 2008

Address for correspondence:

Clive Seale, School of Social Sciences, Brunel University, Uxbridge, Middlesex UB8 ${ }_{3} \mathrm{PH}$, UK

Email: clive.seale@brunel.ac.uk 